\title{
Preparing Engineering Students for the Global Sourcing Environment
}

\author{
https://doi.org/10.3991/ijac.v10i1.5942 \\ L. Manzione \\ University of Hartford, West Hartford, CT, USA \\ manzione@hartford.edu \\ A. Abu-aisheh \\ University of Hartford, West Hartford, CT, USA \\ abuaisheh@hartford.edu \\ N. Sumukadas \\ University of Hartford, West Hartford, CT, USA \\ sumukadas@hartford. edu \\ S. Congden \\ University of Hartford, West Hartford, CT, USA \\ congden@hartford.edu
}

\begin{abstract}
Globalization and rapid changes in modern product development and realization are creating gaps in engineering education systems around the world. The global economy has changed the way that engineering firms design, develop, and produce their products. Companies need to evaluate many options available worldwide, not just locally. The current trends are only likely to continue as the world economy becomes more competitive, interdependent, and characterized by global relationships among supply chain partners. This paper presents a plan for preparing engineering students for the new global sourcing environments and product realization processes. Infusions of supply chain management and project management skills into the curriculum are recommended, as well as use of university-industry partnerships, course portfolios, and study abroad programs.
\end{abstract}

Keywords-engineering education, global sourcing, supply chain management, project management.

\section{Introduction}

Engineering education today is facing an unprecedented array of challenges. Today's continuously changing world with ever increasing globalization has upended the 
environment in which engineers have traditionally operated. In the face of such upheaval, an important question to address is how engineering education programs need to respond to these sea changes. Universities are constantly playing the game of catch up. While scrambling to prepare engineering students for this new era of globalization, the speed of change in the global environment very quickly outpaces the snail's pace of curricular reform.

The development of a pipeline of engineers with the necessary skills to operate in today's environment cannot really occur without paying close attention to the needs of industry. A new generation of engineers will need skills in areas such as project management, supply chain management, technology evaluation, quality engineering and product testing, among others. Engineering students will become employees who will need to know how to operate in the world of multiple simultaneous product lines, global sourcing, and extensive customer and partner interfacing.

In this paper, we present a strategic plan for preparing engineering students for the new global sourcing environment. This plan includes: Supply Chain Management (SCM) training; Project Management (PM) training; university-industry partnerships; course portfolios; and study abroad.

\section{The Global Sourcing Environment}

"Thirty years ago, many large firms were vertically integrated, meaning they owned some of their suppliers and/or customers. Today, this practice is much less common" [1, pp. 5]. Indeed, in today's world "the typical manufacturer spends more than 60 percent of its total income from sales on purchased services and materials" [2, pp. 362]. In some industries, this figure can be "as high as 80 percent or more" [3, pp. 1]. Not surprisingly, "integrating suppliers and customers ... is critical in today's increasingly competitive environment" [4, pp. 213]. Unfortunately, companies are finding that "knowing this and doing it are two different matters" [4, pp. 213]. Given such a complex context, it is easy to see why engineering students need training to meet the new demands of this changing environment.

In addition to increasing reliance on outside suppliers, companies are increasingly selecting these outside sources from around the world. The new global business realities have created a global sourcing environment where firms need to adopt global sourcing strategies [5]. Accelerating these global trends are improved transportation, cost effective global delivery services, broadband networks, and information links, all of which are continuously eroding the barriers of time and space.

Global sourcing has affected not just purchasing practices, but also the entire way that firms design, develop, and produce their products. For example, a shift in business model from purchasing raw materials to purchasing assembled components will have significant implications for the redesign of a company's processes. While communications technologies and convergence in business practices facilitate global sourcing of materials and assembled components, they also permit simultaneous participation in technical or product development projects from personnel from around the world, both from within and from outside a company. 
Several studies have commented on the impact of globalization on supply chains for high-tech production lines [6][7][8]. The new realities mandate that companies evaluate design, development, and realization options from across the world. A plethora of areas within the company are bound to be affected, such as facility location, capacity planning, global bills of materials, duties, and local content requirements, among others [9]. Even the new product development (NPD) process has changed. NPD collaboration nowadays often spans corporate, regional, and national boundaries. Boeing's 7E7 program, for example, involved 30 companies and spanned 8 countries [10].

It is within this global sourcing environment that engineering students must learn how to operate. These trends will only increase as the world economies become more interrelated, more competitive, and more interdependent. In such an environment, engineers must regularly prepare specifications and sources sought documents, communicate specifications to potential partners and suppliers, conduct technical evaluations on the multitude of global solutions available to them, assess capabilities of suppliers and partners, develop testing plans, as well as operate in different nations and cultures. To achieve that goal, their preparation should give them opportunities to master how to work in real life supply chain management.

\section{Current Gaps In Engineering Education}

We now proceed to examine engineering education programs in the context of the global environment described above. Taking a critical viewpoint, we notice that too many programs are not designed to provide students with the skills necessary to successfully operate in this new environment. Most significantly, students lack exposure to the skills necessary for operating within modern, global supply chains.

In addition to the above deficiency, we also notice some other important gaps. These gaps are also, in many respects, related to the global context. They include:

1. Inadequate emphasis on translating technical challenges to Requests for Proposals (RFPs) and Specifications.

2. Inadequate emphasis on technical evaluation of offered solutions.

3. Inadequate emphasis on business case vs. technical specification trade-offs.

4. Inadequate emphasis on systems engineering and industrial engineering.

5. Significant lack of Quality Engineering and Product Testing Statistics.

6. Inadequate emphasis on Design for Manufacturing (DFM).

7. Inadequate emphasis on sustainable engineering solutions, and environmental impact of products, and processes to produce them.

To address such gaps in current engineering education programs, we propose a strategic plan that includes curriculum changes as well as teaching strategies. The changes are:

1. Training in Supply Chain Management (SCM) skills

2. Training in Project Management (PM) skills 
3. University-Industry partnerships

4. Course portfolios

5. Study abroad

\section{Supply Chain Management (SCM) Skills}

As noted earlier, SCM has become an essential skill set for managers of global enterprises involved with the flow of goods and services towards fulfilling customers' needs. SCM is the management of all activities involved in the sourcing of materials, the production of products, as well as the distribution of the products through wholesalers, distributors and retailers to the end user. It utilizes the methods of logistics and operations research to construct supply chains using holistic approaches that realize value at all nodes of the chain.

Robust supply chains allow businesses to deliver the most cost competitive and timely solutions to their customers by leveraging the capabilities of the multiple linkages in their supply chain. Many companies find that it is preferable to specialize in an area where they offer distinct advantages, while relying on supply chain partners for other specializations. By combining strengths, together they can create the best offer for the customer. Thus, in today's highly competitive global business climate, dominated by multiple sourcing, effective and robust supply chains are essential for companies to leverage their supply chain partners to meet customers' needs.

As companies are increasingly recognizing the need for SCM skills at all levels of the organization, engineering and business education programs across the nation are growing their offerings in SCM and the related discipline of logistics. While many different programs exist, with different flavors, we present an example that we have developed at our university. Working collaboratively, the engineering and business schools have developed a program in SCM that allows students to earn a postgraduate certificate or a concentration. This program is focused on developing a portfolio of SCM skills that are indispensable in the current complex business and engineering environment dominated by globalization and outsourcing.

The SCM program consists of four graduate courses (12 credit hours). Students enrolled in our M.Eng. program, as well as others with a prior undergraduate degree in engineering, can earn a post-graduate SCM certificate. Meanwhile, students enrolled in our MBA program can earn an SCM concentration within their MBA. As well, students already having an MBA from an accredited institution can complete a postgraduate SCM certificate.

Engineering and business students can enroll in the same courses, allowing them to learn with and from each other, and gain an interdisciplinary experience that promotes career readiness. Both engineering and business faculty teach courses to create a cross-functional learning environment. The program also includes a capstone course where students apply their skills to a process improvement project.

All students need a prerequisite course in Engineering or Managerial Statistics. In addition, students must complete four required courses in Operations Management, 
Supply Chain Management or Supply Chain Engineering, Lean Six Sigma Principles, and a Process Improvement Application Project.

\section{$5 \quad$ Project Management (PM) Skills}

"Projects are common in everyday life as well as in business" [2, pp. 50]. This statement is especially true in an engineering context. The engineer is constantly in the middle of some project or the other, whether it be a technology innovation project, NPD project, process improvement project, lean project, six sigma project, or a simple kaizen event. Thus, it is not an understatement to say that PM skills are essential elements of an engineer's toolkit. With the increasing demand in a world economy to combine different tools for implementing projects, there is a greater need today for skilled project managers to improve company performance.

Globalization means that "many projects now involve global teams whose members operate in different countries and different time zones, each bringing a unique set of talents to the project" [11, pp. 3]. "For example, Boeing created global supplier/strategic partner teams for their new 787 Dreamliner aircraft to co-design and produce various portions of the new plane: the vertical in Seattle, WA, the cockpit in Wichita, KS, the wings in Japan, and the center fuselage in Italy" [11, pp. 39].

Thus, PM skills are important for both business and engineering students. In order to satisfy student and employer demand for knowledge and skills related to PM, many business schools are offering graduate level courses, and even complete degree programs, in PM. Some schools started out by offering concentrations in PM, and then expanded to MS programs. As with SCM programs, many different flavors can be found.

Once again, we present an example that we have developed at our university. Our PM program offers content similar to others, but is designed to be multidisciplinary. As with our SCM program, both engineering and business students can enroll in the same courses. Both engineering and business faculty teach the courses in a crossfunctional learning environment similar to business settings where projects are managed. In addition, we decided to align the course content closely with the Project Management Institute's (PMI) certifications, namely Project Management Professional (PMP) and Certified Associate in Project Management (CAPM). Thus, students completing the program qualify to take either the PMP or CAPM exam, depending on their prior project work experience, and are encouraged to do so. PMI certification signifies that students have achieved a recognized standard of global best practices.

The PM program consists of four graduate courses (12 credit hours). Students enrolled in our M.Eng. program, as well as others with a prior undergraduate degree in engineering, can earn a post-graduate PM certificate. Meanwhile, students enrolled in our MBA program can earn a PM concentration within their MBA. As well, students already having an MBA from an accredited institution can complete a post-graduate PM certificate.

All students need a prerequisite course in Engineering or Managerial Statistics. In addition, students will complete four required courses in Operations Management, 
Managerial Skills and Project Leadership, Project Risk Management, and Lean Six Sigma Principles.

\section{University-Industry Partnerships}

An important element in preparing students for a dynamic and global environment is the building of partnerships between universities and industry. These can take several forms. At a basic level, industry experts can be brought into classrooms as guest speakers or students taken on field trips.

A higher level would be student internships. Student motivation can be heightened by experiencing "real world" work settings, especially if students can see the application and relevancy of what they have learned in the classroom. There are many other benefits to students (e.g., finding good employment), but we focus here on the benefits related to making them better prepared for an increasingly dynamic and global work environment. (For a more complete review of the benefits and costs of internships to relevant stakeholders, see [12]).

At the higher end of the university-industry partnership spectrum, schools must actively seek industry involvement in curriculum development. Employers are on the front lines of change. The surest way to keep educational outcomes current and in tune with rapidly evolving industry requirements is to regularly revamp course offerings based on input from industry experts. Interaction should happen on many levels: Deans with advisory boards, curriculum committees/taskforces with either ad hoc or standing industry panels, individual professors with companies to whom they consult or do projects with, internship coordinators with employers, and so on. Our project management and supply chain management concentrations discussed above were refined with feedback from industry personnel.

Using the input of industry experts together with internships can create a virtuous circle. Companies can guide the relevancy of curriculum choices, which then allows students to experience more linkages between course work and their internship experiences. Better prepared and motivated students, along with other benefits to employers such as the ability to trial potential hires, should stimulate more internship offerings. Better internships and eventual job offers should attract better quality students to a college of engineering, and so on. A key part of this is that more involvement by employers gives them a larger stake in student outcomes and hopefully motivates deeper reflection on their part about curriculum.

This is not without costs. We believe at least a full time internship coordinator role should be done at the college level rather than relying on University-wide career placement services. Careful cultivation of quality internships specific to the needs of engineering students needs to take place. Much direct interaction of the engineering college with employers will be needed to provide the right internship leaning experiences and to make sure feedback from the "real world" world is not lost. We believe that giving course credit for internships better communicates their importance to stakeholders. Project-based work formats as opposed to job-based work formats (see [12]) are preferable given the increasing importance of project management skills. 
International engineering internships would be ideal in increasing a global perspective but would be difficult arrange on any large scale.

\section{$7 \quad$ Course Portfolios}

A course portfolio is a document prepared by a student that summarizes each chapter in the course. Preparing a course portfolio forces students to engage in deeper learning, as they have to understand the material thoroughly before they can rewrite it in their own words. A related benefit has to do with improving students' technical writing skills.

Writing skills are essential in any engineering context since the consequences of miscommunication can be expensive. In a globally dispersed supply chain, these consequences can get magnified. Consider a simple example: A sends an email to a supplier, B; B doesn't understand the email; but B is on a different time zone, so B cannot just pick up the phone to clarify the doubt; and so on. Given that a significant amount of engineering disciplinary knowledge cannot be communicated without strong technical writing, having excellent technical writers in the work place is important for seamless collaboration.

A course portfolio also allows instructors to evaluate students' understanding of course material. A helpful way to implement a course portfolio is to let students know that they can use only the course portfolio on the exam, and nothing else. To ensure that students differentiate between important topics and others, students can be asked to limit the length of each chapter portfolio.

\section{Study Abroad}

Several authors have written about the changing role of engineers in today's evolving global environment [13][14][15]. This new role requires engineers to exhibit a greater appreciation of the tremendous variety of cultures, customs, and ways of operating that exist around the world. In contrast to universities in Europe, where many students not only gain fluency in multiple languages, but are also able to gain experiences in multiple nations and cultures, U.S. universities have been criticized for not preparing students with a global outlook. A great way to help engineering students think globally is to have them engage in study abroad experiences. No amount of reading about a distant place can substitute for the real thing.

To obtain a better understanding of the emerging global environment, it is important for students to develop an understanding of the world and the challenges faced by different regions, and the forces that hold them in balance. For example, technological challenges like climate change and sustainable energy sources can take on entirely different meanings in different contexts, with entirely different implications. Study abroad can provide students better insights into global marketplaces, economic trends, the availability and use of resources in different regions, and other factors that influence the success of technological ventures in different parts of the world. Stu- 
dents also gain confidence and motivation to engage in further international undertakings.

While longer term study abroad programs (generally eight weeks or more) provide these benefits, it may not be practical for many students given time and/or financial constraints. Our strategy recommends the use of shorter-term programs. Short-term study abroad programs can increase participation and be done outside of the semester format. This is especially important for more structured programs like engineering [16]. While the benefits of longer-term study abroad are more accepted because of longer in-country experience, a study of 6,378 former study abroad participants found no significant difference in global engagement related to the duration of the programs; depth and intensity of the experience are what mattered most [17]. Short term programs often offer the advantage of being led by faculty from the home university, and can be controlled and structured to maximize student experiences during the time abroad, require ongoing reflection, and better integrate with student's course work [16]. Short-term programs would also better allow students to have more than one study abroad experience, for example in both a developed and developing country.

We have had short-term study abroad programs in both developed and developing countries. One program sent engineering students to Germany to study how that country is using alternative and renewable energy. In a project led by our student chapter of Engineers Without Borders, students designed a solar-powered ground water pump system, and then traveled abroad to India to install it in a village. This program combined the benefits of study abroad and problem-based learning. Given limitations in what study abroad opportunities can be offered and/or sufficiency of students to make a particular trip viable, students are also encouraged to participate in study abroad opportunities in other schools such as the university's school of business.

An important aspect of providing maximum depth of experience during the trip is on-campus components before and after the experience. While also meeting course contact hour requirements, study beforehand can establish a base level of learning that heightens perceptions of international issues during the visit. Prior leaning could take many forms depending the nature of the program, such as differences in business/infrastructure context, the design phase of a problem-based learning project, culture, history, and even basic language instruction. Post-trip components provide a chance for reflection, exchange of experiences, and project presentations. The Florida Institute of Technology even uses online synchronous and asynchronous meetings before and after to extend opportunities to more students, such as part-time students, students from satellite campuses, or even from other universities to attain sufficient numbers of students to run a particular study abroad course [18].

\section{Conclusion}

In many respects, the world today is indeed flat [13]. Skilled human talent is more globally mobile than ever before. Consider what happened during the global financial crisis when thousands of project management professionals in Hong Kong were displaced by lower wage talent from China [11][19]. "As a result, Hong Kong PMs are 
finding that they need to increase their value to business in order to compete with the new arrivals from China" [19, pp. 43].

Extending this logic to engineering education, universities need to be constantly aware of global shifts in demand for skills. In an era when even highly skilled professionals find themselves expendable, what to talk of engineering graduates who lack the necessary skills?

Many US companies are already accustomed to hiring global talent. The term "outsourcing" has become a common buzzword, not just in the manufacturing sector, but in several diverse fields as well. In the software field, for example, technology companies cite a lack of skilled local software talent as they continue to petition the government to issue more visas. Meanwhile, local software professionals bemoan depressed wages. On a similar somber note, unless engineering students are adequately trained for a global environment, it is no stretch of the imagination that companies will seek talent elsewhere. It is crucial, therefore, that universities prepare their graduates to operate in this new global environment.

In this paper we presented a strategic plan that will help better prepare engineering students for the new global sourcing environment. As we have outlined, universities can implement curricular changes that include training in SCM and PM skills. We also recommend the adoption of learning strategies such as university-industry partnerships, course portfolios, and study abroad.

\section{References}

[1] J. D. Wisner, K. C. Tan and G. K. Leong, Principles of Supply Chain Management: A Balanced Approach, 4th ed. Boston, MA: Cengage Learning, 2016.

[2] L. J. Krajewski, L. P. Ritzman and M. K. Malhotra, Operations Management: Processes and Supply Chains, 10th ed. Upper Saddle River, NJ: Pearson Education, 2013.

[3] M. G. Anderson and P. B. Katz, "Strategic sourcing," Int. J. Log. Manage., vol. 9, no. 1, pp. 1-13, 1998. https://doi.org/10.1108/09574099810805708

[4] D. Searcy, B. Greene and J. Reeve, "Taming the aerospace supply chain - A case study in organizational integration," Defense Acquisition Review J., pp. 212-228, 2004.

[5] R. J. Trent and R. M. Monczka, "Pursuing competitive advantage through integrated global sourcing," Acad. of Manage. Exec., vol. 16, no 2, pp. 66-80, 2002. https://doi.org/10.5465/AME.2002.7173538

[6] B. Arntzen, G. Brown, T. Harrison and L. Trafton, "Global supply chain management at Digital Equipment Corporation," Interfaces, vol. 25, no.1, pp. 69-93, 1995. https://doi.org/10.1287/inte.25.1.69

[7] B. Beamon and C. Fernandes, "Supply-chain network configuration for product recovery," Prod. Plan. and Control, vol. 15, no. 3, pp. 270-281, 2004. https://doi.org/10.1080/ 09537280410001697701

[8] M. Cohen and A. Huchzermeier, "Global supply chain management: a survey of research and applications," in S. Tayur, R. Ganeshan and M. Magazine (Eds.), Quantitative Models for Supply Chain Management. Boston, MA: Kluwer Academic Publishers, pp. 670-702, 1998.

[9] J. Goentzel, L. Manzione, R. Piberink, J. Pruett and B. Thiessen, "Strategic development of specialized testing and remanufacturing in a global high tech supply chain," Int. J. 
Manuf. Tech. and Manage., vol. 11, no. 1, pp. 28, 2007. https://doi.org/10.1504/ IJMTM.2007.012445

[10] Reprogramming Aerospace and Defense, IBM Business Consulting Services, White paper, 2004.

[11] J. R. Meredith, S. M. Shafer, S. J. Mantel and M. M. Sutton, Project Management in Practice, 5th ed. Hoboken, NJ: John Wiley \& Sons, 2010.

[12] C. P. Maertz Jr, P. A. Stoeberl and J. Marks, "Building successful internships: lessons from the research for interns, schools, and employers," Career Development International, vol. 19, no. 1, pp. 123-142, 2014. https://doi.org/10.1108/CDI-03-2013-0025

[13] T. Friedman, The World is Flat: A Brief History of the Twenty-first Century. Farrar, Straus, and Giroux, 2005.

[14] National Academy of Engineering, The Engineer of 2020: Visions of Engineering in the New Century. Washington, DC: National Academies Press, 2004

[15] Council on Competitiveness, Innovate America: Thriving in a World of Challenge and Change. Washington, DC: National Innovation Initiative Summit, 2005.

[16] L. Donnelly-Smith, "Global learning through short-term study abroad," Peer Review, vol. 11 , no. 4, pp. 12-15, 2009.

[17] R. M. Paige, G. W. Fry, E. Stallman, J-E. Jon and J. Josić, Beyond Immediate Impact: Study Abroad for Global Engagement (SAGE). Report submitted to the Title VI: International Research and Studies Program, U.S. Dept. of Ed., pp.1-214, 2010.

[18] M. H. Slotkin, C. J. Durie and J. R. Eisenberg, "The benefits of short-term study abroad as a blended learning experience," J. Int. Educ. in Bus., vol. 5, no. 2, pp. 163-173, 2012. https://doi.org/10.1108/18363261211281762

[19] S. A. Swanson, “On the map,” PM Network, November 2009.

\section{Authors}

Louis Manzione is the Dean of the College of Engineering, Technology, and Architecture at the University of Hartford. He has a B.E. degree in Chemical Engineering from the Cooper Union, and a PhD in Chemical Engineering from Princeton University. Prior to coming to the University of Hartford, he was with Bell Labs Research in Murray Hill, New Jersey. He was the founding Executive Director of their new Bell Labs Ireland division near Dublin. His research activities have been in the areas of micoelectronics and manufacturing. He has 17 US Patents, and a number of these have been commercialized into millions of AT\&T and Alcatel-Lucent products. In Connecticut, he is the Chair of the Connecticut Engineering Deans Council, and he is Past-President of the Connecticut Academy of Science and Engineering (manzione@hartford.edu).

Akram Abu-Aisheh is an Associate Professor of Electrical and Computer Engineering at the University of Hartford. Professor Abu-aisheh is a senior IEEE member, and he has ten years on industry experience in the area of fiber optic telecommunication systems and power electronics. Proressor Abu-aisheh's research interests include optical communications and power electronics. Professor Abu-aisheh has a M.S. and B.S. degrees in Electrical Engineering from the University of Florida and a Ph.D. in from the Florida Institute of Technology (abuaisheh@hartford.edu). 
N. Sumukadas is with Barney School of Business, University of Hartford, West Hartford, CT, USA (sumukadas@hartford.edu).

S. Congden is with Barney School of Business, University of Hartford, West Hartford, CT, USA (congden@hartford.edu).

This article is an extended and modified version of a paper presented at the EDUCON2016 conference held in Abu Dhabi, UAE, 10-13 April 2016. Article submitted 12 December 2016. Published as resubmitted by the authors 23 February 2017. 